\title{
FIELD CANCERIZATION- AN APPRAISAL OF CONCEPTS AND RESEARCH
}

\author{
Ananthaneni Anuradha1, Pratibha Ramani2, Guduru Vijay Srinivas ${ }^{3}$, Undavalli Suresh Babu', Mohammed Asif Kiresur ${ }^{5}$
}

1Ph.D Scholar, Department of Oral Pathology, Saveetha Dental College, Chennai, Tamilnadu, India.

2Professor and HOD, Department of Oral Pathology, Saveetha Dental College, Chennai, Tamilnadu, India.

3 Professor and HOD, Department of Oral Pathology, St. Joseph Dental College, Eluru Andhra Pradesh, India.

${ }^{4}$ Associate Professor, Department of ENT, Dr. Pinnamaneni Siddhartha Institute of Medical Sciences, Vijayawada, Andhra Pradesh,

India.

${ }^{5}$ Reader, Department of Oral Pathology, St. Joseph Dental College, Eluru Andhra Pradesh, India.

\section{BACKGROUND}

ABSTRACT

A large area of the genetically altered area around the tumour proper that appears clinically normal is called field cancerization. This field subsequently influences the prognosis as it can root to second field tumours i.e. recurrence or second primary tumours. Field cancerization has been described in the oral cavity, oropharynx, larynx; lung, vulva, oesophagus, cervix, breast, skin, colon and bladder. Studies have shown a comparatively higher frequency of local recurrences and second primary tumours after surgical resection in betel chewers than non-chewers probably due to the existence of field cancerization.

\section{KEY WORDS}

Field, Micrometastasis, Second Primaries.

HOW TO CITE THIS ARTICLE: Anuradha A, Ramani P, Srinivas GV, et al. Field cancerization- an appraisal of concepts and research. J. Evolution Med. Dent. Sci. 2018;7(53):5639-5642, DOI: 10.14260/jemds/2018/1247

\section{BACKGROUND}

Oral cancer $(\mathrm{OC})$ includes a diverse group of tumours arising from the oral cavity. It is the $11^{\text {th }}$ most common malignancy in the world(1) and $12^{\text {th }}$ most pervasive cancer in Asia.(2) The widely prevalent risk factor is the use of tobacco in varied forms like smoking and smokeless with associated intake of alcohol.(3) Tobacco is responsible for approximately $22 \%$ of cancer deaths.(4) An important risk factor for oral and oesophageal cancers is smokeless tobacco,(5) with nearly 160 million Indian users and an alarming increase in child and young adult users according to Global Adult Tobacco Survey (GATS) by the Ministry of Health and Family Welfare in November 2010. Oral potentially malignant disorders (OPMD) like leucoplakia, erythroplakia, submucous fibrosis and lichen planus often foreshadow OSCC. OPMD that are allied with tobacco chewing, smoking and alcohol are vulnerable to field changes. Field cancerization (FC) also termed as cancer field effect or premalignant field defect is defined as a biological process in which a large area of cells in a tissue or within an organ is affected by carcinogenic alterations. These alterations develop in a stepwise manner starting from benign hyperplasia to dysplasia followed by carcinoma in situ to invasive cancer. Slaughter and his associates were the pioneers of the concept of field cancerization which evolved based on the occurrence of multiple primary tumours in the tumour-associated mucosa (TAM), synchronous or metachronous distant second tumours, multiple recurrences and persistence of tumours.(6)

'Financial or Other Competing Interest': None.

Submission 23-11-2018, Peer Review 18-12-2018,

Acceptance 24-12-2018, Published 31-12-2018.

Corresponding Author:

Ananthaneni Anuradha,

Ph.D Student,

Department of Oral Pathology,

Saveetha Dental College, Chennai,

Tamilnadu, India.

E-mail: anuradhaundavalli@yahoo.com

DOI: $10.14260 /$ jemds $/ 2018 / 1247$

\section{Evolutionary Concepts of Field Cancerization}

The cellular basis of FC is explained based on two postulated models. According to the 'polyclonal model', exposure of the oral cavity to carcinogens will lead to multiple genetic abnormalities in the entire area lending the whole mucosa liable for development of multiple SCC independent of each other. This concept was confronted because molecular analysis of some distant synchronous or metachronous tumours, recurrences and skip lesions gave an impression of origin from a common progenitor.(7)

The 'monoclonal model' proposes that genetic mutations befall in a single cell delivering a growth advantage over other neighboring cells and succeeding progeny share the same initiating genetic event. Pertinent to the tumour growth, the subclones precipitate additional genetic changes leading to heterogeneity. The reformed cells of subclones then migrate and develop multiple lesions. The migration of dysplastic and altered cells may occur in three different patterns: i) saliva may serve as a mediocre for relocation of malignant cells (Micrometastasis); ii) the heirs of initially transformed malignant cells may parade intra-epithelially (Lateral Spread) iii) migration may be through the submucosa.(8),(9) Diversified research in FC with a considerable number of proposed models is because of meager understanding of its propagation. The extent of the field may be as large as $7 \mathrm{~cm}$ around the carcinoma or in oral cancer it may extend not only through the entire upper aerodigestive tract but also deep into the respiratory system.(10)

Cancer stem cell (CSC) is centered in the Cancer stem cell model of carcinogenesis and this idea is enriched by increased expression of the pluripotent stem cell markers like OCT4, SOX2, NANOG in HNSCC cell lines and other CSC markers like ABCG2, CD44, and ALDH1 that are proverbial to have tumour-inducing potential. CSC is tailored with unlimited self-renewal; slow dividing capacity and is envisioned to originate either by several genetic and epigenetic alterations or precancerous phenotypic transformation in a normal, tissue-specific stem cell or by dedifferentiation of mature tumour cells. CSC markers like ATR, 
ABCG1, OCT4, and SOX2 are also expressed in tumourassociated mucosa authenticating their role in $\mathrm{FC}$ and hence CSC driven field cancerization model was contemplated. The process of field cancerization is initiated by a carcinogenic hit at $17 \mathrm{p}$ (TP53) and 3p/9p (p16/FHIT) transforming a normal stem cell into CSCs which proliferate and primarily form a patch of transit amplifying cell (TAC). A subsequent hit at $13 q$, the location of the $\mathrm{Rb}$ gene leads to the formation of a primary tumour. The field progresses because of the monoclonal or polyclonal mode of propagation. The CSC in the field can migrate sideways to outgrow the field or get implanted at a different site and form a genetically analogous tumour portentous of the monoclonal mode of field cancerization. Alternatively, multifarious hits to normal stem cells in the epithelium will lead to the development of distinct independent clones signifying the polyclonal mode.(11)

During organ development, epithelial-mesenchymal interactions play a critical role and in this contextual, contribution of stroma in carcinogenesis was scrutinized. Incentives that root mutations in the epithelium also precipitate similar changes at genetic or epigenetic levels in the neighboring stroma. Hence a novel carcinogenesis model of field cancerization that focuses on the effect of activated stroma that contains carcinoma-associated fibroblasts (CAFs) harboring permanent epigenetic alteration was proposed. An upsurge in the existing tumour CAFs or outstanding CAF cells after surgical removal of the tumour is reasoned for development of multiple primary tumours (MPTs) or second primary tumour (SPTs). The proteins that they express like FAP, Carbonic Anhydrase IX, SPARC, AR, and Podoplanin are critically evaluated.(12)

Field Cancerization has been hypothesized as an amplification of biochemical abnormalities owing to the development of cancer cells. The proteomic changes are considered as biochemical abnormality at the cellular level. For e.g. transformed cells maintain sufficient oxygen levels for tumour growth and metastasis by conveying abnormal or altered cell signals to normal cells in order to promote an increase in the VEGF production and inhibition of the immune system. This colloquy between normal and transformed cells at the protein level is maintained until the transformed cells are viable and the normal cells amplify the biochemical anomalies that pacify the growth of transformed cells.(13) Even changes in salivary pH can induce proliferative changes in the tissue due to its preconditioning effect wherein the mucosa becomes susceptible to the action of even a weak carcinogen. Such a mucosa is known as preconditioned mucosa or condemned mucosa. Most common preconditioning factor is exposure to carcinogens like the tobacco products, but chronic inflammation which forms an integral component of lesions such as oral Lichen Planus and microorganisms may also have a high prospect of developing multiple oral squamous cell carcinoma due to their preconditioning effect.(14)

\section{Investigations}

The light microscopic examination of biopsies from tumourassociated mucosa elicited morphological changes like an increase in nuclear size, discontinuous nuclear membrane, numerous Feulgen-negative areas, absence of a single large nucleolus and a reduction in cytoplasmic area.(15),(16) Electron microscopic studies also affirmed the presence of morphologic abnormalities consistent with the multistep concept of carcinogenesis.(17) Thenceforth a number of methods and stains were used to demonstrate field cancerization like supravital staining with toluidine blue,(18) vital staining with iodine(19) and special stains like AgNOR.(20) Fluorescence in situ hybridization(21) and microsatellite analysis(22) of cells obtained from tumour-associated mucosa exhibited chromosomal aberrations and polysomies of chromosome 7 and 17.(23)

Immunohistochemical analysis of proliferative markers like Ki67,(24),(25),(26) and PCNA(27) forecasted an increased proliferation rate in the tumour-associated mucosa. Expression of Epidermal growth factor receptor (EGFR) ${ }^{(9)}$ and one of its ligand TNFa is also enhanced.(28) Cyclin D1 which regulates $\mathrm{G}_{1}$ to $\mathrm{S}$ transition in the cell cycle is overexpressed in TAM.(29) Abundant clusters of P53 positive cells were evidenced in TAM,(30),(31),(32) with contemporaneous studies demonstrating a lack of $\mathrm{Bcl} 2$ expression. (33) The expression of all Glutathione $S$ transferase isoenzymes was significantly higher in normal mucosa adjacent to OSCC.(34) Aberrant expression of cytokeratins is not only seen in OSCC but also apparently normal mucosa in smokers. (35) The epithelium of fetal buccal mucosa and tongue express cytokeratin 8 and 18 normally until 27 weeks of gestation. During malignant transformation where the cells undergo dedifferentiation, there is the return of embryonic pattern of expression that is enhanced expression of cytokeratin 8 and 18 is seen in OSCC and well as $80 \%$ of the tumour-associated mucosa. Moreover, epithelial differentiation dysfunctional marker, cytokeratin 19 and matrixmetallo proteinase 9 (MMP9) are also overexpressed.(36) A 2.2 fold increase in protein tyrosine kinase activity and a 1.7 fold elevated ratio of protein tyrosine kinase activity to protein tyrosine phosphatase activity was observed in TAM.(37)

Field Cancerization may elude macroscopic or histopathological examination and the genetically altered cells in this region may require refined molecular approaches such as whole exome sequencing (WES) and targeted ultradeep sequencing (UDS),(38) DNA amplification techniques, in situ hybridization and cytogenetic analysis. FC has been delved by means of PCR for determining $\mathrm{LOH},(39),(40),(24) \mathrm{FISH}$ multiplex ligation-dependent probe amplification (MLPA) which allows the measurement of numerical chromosomal alterations, gains and losses, at up to 40 target locations in a single PCR run(41) and DNA ploidy assays. (43) Grounded on the genetic analysis, FC can be deliberately staged into a clonal unit with TP53 i.e. 9p21 mutations demarcated as altered precursor lesion or benign squamous hyperplasia, followed by other genetic mutations in $3 \mathrm{p} 21$ and $17 \mathrm{p} 13$ leading transformation into dysplasia. Further for progression into carcinoma in situ, amplification of 11q13, 13q21 and 14q3132.1 is important and for transformation into cancer mutations in $6 p, 8 q, 8 p$ and $4 q 26-28$ chromosomes are needed.(42)

\section{CONCLUSION}

Thus, the literature review supports the existence of large areas of the genetically altered field around the tumour proper whilst appearing clinically normal. This field 
subsequently influences the prognosis as it can root to second field tumours i.e. recurrence or second primary tumours. To impart a concealed field which cannot be deciphered by histopathologic inspection, a number of molecular and genetic studies have been executed. If detected early and watched precisely, implications of second primary tumours can be prevented.

\section{REFERENCES}

[1] Ghantous Y, Elnaaj AI. Global incidence and risk factors of oral cancer. Harefuah 2017;156(10):645-9.

[2] Gupta N, Gupta R, Acharya AK, et al. Changing Trends in oral cancer - a global scenario. Nepal J Epidemiol 2016;6(4):613-9.

[3] Shield KD, Ferlay J, Jemal A, et al. The Global Incidence of lip, oral cavity and pharyngeal cancers by subsite in 2012. CA Cancer J Clin 2017;67(1):51-64.

[4] Forouzanfar MH, Afshin A, Alexander LT, et al. Global, regional and national comparative risk assessment of 79 behavioural, environmental and occupational and metabolic risks or clusters of risks, 1990-2015: a systematic analysis for the Global Burden of Disease Study 2015. Lancet 2016;388(10053):1659-724.

[5] Gakidou E, Afshin A, Abajobir AA, et al. Global, regional and national comparative risk assessment of 84 behavioural, environmental and occupational and metabolic risks or clusters of risks, 1990-2016: a systematic analysis for the Global Burden of Disease Study 2016. Lancet 2017;390(10100):1345-422.

[6] Slaughter DP, Southwick HW, Smejkal W. Field cancerization in oral stratified squamous epithelium: clinical implications of multicentric origin. Cancer 1953;6(5):963-8.

[7] Bedi GC, Westra WH, Gabrielson E, et al. Multiple head and neck tumours: Evidence for a common clonal origin. Cancer Res 1996;56(11):2484-7.

[8] Fearon ER, Vogelstein B. A genetic model for colorectal tumourigenesis. Cell 1990;61(5):759-67.

[9] Van Oijen MG, Slootweg PJ. Oral field cancerization: carcinogen-induced independent events or micrometastatic deposits? Cancer Epidemiology Biomarkers and Prevention 2000;9(3):249-56.

[10] Griffioen GH, Louie AV, de Bree R, et al. Second primary lung cancers following a diagnosis of primary head and neck cancer. Lung Cancer 2015;88(1):94-9.

[11] Simple M, Suresh A, Das D, et al. Cancer stem cells and field cancerization of oral squamous cell carcinoma. Oral Oncology 2015;51(7):643-51.

[12] Ge L, Meng W, Zhou H, et al. Could stroma contribute to field cancerization? Med Hypotheses 2010;75(1):26-31.

[13] Fernández PJ, Méndez-Sánchez SC, Gonzalez-Correa $\mathrm{CA}$, et al. Could field cancerization be interpreted as a biochemical anomaly amplification due to transformed cells? Med Hypotheses 2016;97:107-11.

[14] Mignogna MD, Fedele S, Lo Russo L, et al. Field cancerization in oral lichen planus. Eur J Surg Oncol 2007;33(3):383-9.

[15] Ogden GR, Cowpe JG, Green MW. The effect of distant malignancy upon quantitative cytologic assessment of normal oral mucosa. Cancer 1990;65(3):477-80.
[16] Ogden GR, Cowpe JG, Green MW. Detection of field change in oral cancer using oral exfoliative cytologic study. Cancer 1991;68(7):1611-5.

[17] Incze J, Vaughan CW Jr, Lui P, et al. Premalignant changes in normal appearing epithelium in patients with squamous cell carcinoma of the upper aerodigestive tract. Am J Surg 1982;144(4):401-5.

[18] Strong MS, Incze J, Vaughan CW. Field cancerization in the aerodigestive tract--its etiology, manifestation and significance. J Otolaryngol 1984;13(1):1-6.

[19] Nomura T, Shibahara T. Detection of field alterations using useful tools for oral squamous cell carcinoma. Jpn Dent Sci Rev 2013;49(3):106-15.

[20] López-Blanc SA, Collet AM, Gandolfo MS, et al. Nucleolar organizer regions (AgNOR) and subepithelial vascularization as field cancerization markers in oral mucosa biopsies of alcoholic and smoking patients. Oral Surgery Oral Med Oral Pathol Oral Radiol Endodontology 2009;108(5):747-53.

[21] Ai H, Barrera JE, Pan Z, et al. Identification of individuals at high risk for head and neck carcinogenesis using chromosome aneuploidy detected by fluorescence in situ hybridization. Mutat Res: Genet Toxicol Environ Mutagen 1999;439(2):223-32.

[22] Lee N, Ye Y, Li X, et al. Allelic loss on chromosome-13 can preceed histological-changes in head and neckcancer. Int J Oncol 1994;5(2):205-10.

[23] Voravud N, Shin DM, Ro JY, et al. Increased Polysomies of Chromosome-7 and Chromosome-17 during head and neck multistage tumourigenesis. Cancer Res 1993;53(12):2874-83.

[24] Tabor MP, Braakhuis BJ, Van der Wal JE, et al. Comparitive molecular and histological grading of epithelial dysplasia of the oral cavity and the oropharynx. J Pathol 2003;199(3):354-60.

[25] Montebugnoli L, Badiali G, Marchetti C, et al. Prognostic value of $\mathrm{Ki} 67$ from clinically and histologically 'normal' distant mucosa in patients surgically treated for oral squamous cell carcinoma: a prospective study. Int J Oral Maxillofac Surg 2009;38(11):1165-72.

[26] Gissi DB, Gabusi A, Tarsitano A, et al. Ki67 Overexpression in mucosa distant from oral carcinoma: a poor prognostic factor in patients with long-term follow-up. J Craniomaxillofacial Surg 2016;44(9):1430-5.

[27] Shin DM, Voravud N, Ro JY, et al. Sequential increases in proliferating cell nuclear antigen expression in head and neck tumourigenesis: a potential biomarker. J Natl Cancer Inst 1993;85(12):971-8.

[28] Grandis JR, Tweardy DJ. Elevated levels of transforming growth factor $\alpha$ and epidermal growth factor receptor messenger RNA are early markers of carcinogenesis in head and neck cancer. Cancer Res 1993;53(15):3579-84.

[29] Bartkova J, Lukas J, Müller H, et al. Abnormal patterns of D-type cyclin expression and G1 regulation in human head and neck cancer. Cancer Res 1995;55(4):949-56. 
[30] Gupta SS, Shetty DC, Urs AB, et al. p53: Revealing the unusual suspect: a study and field cancerization mini review. Indian J Surg Oncol 2014;5(2):144-7.

[31] Nees M, Homann N, Discher H, et al. Expression of mutated p53 occurs in tumour-distant epithelia of head and neck cancer patients: a possible molecular basis for the development of multiple tumours. Cancer Res 1993;53(18):4189-96.

[32] Cruz IB, Snijders PJ, Meijer CJ, et al. P53 expression above the basal cell layer in oral mucosa is an early event of malignant transformation and has predictive value for developing oral squamous cell carcinoma. J Pathol 1998;184(4):360-8.

[33] Birchall MA, Schock E, Harmon BV, et al. Apoptosis, mitosis, PCNA and bcl-2 in normal, leukoplakic and malignant epithelia of the human oral cavity: prospective, in vivo study. Oral Oncol 1997;33(6):41925.

[34] Bongers V, Snow GB, de Vries N, et al. Second primary head and neck squamous cell carcinoma predicted by the glutathione S-transferase expression in healthy tissue in the direct vicinity of the first tumour. Lab Investig 1995;73(4):503-10.

[35] Ogden GR, Lane EB, Hopwood DV, et al. Evidence for field change in oral cancer based on cytokeratin expression. Br J Cancer 1993;67(6):1324-30.

[36] Kale AD, Mane DR, Babji D, et al. Establishment of field change by expression of cytokeratins 8/18, 19 and MMP-9 in an apparently normal oral mucosa adjacent to squamous cell carcinoma: a immunohistochemical study. J Oral Maxillofac Pathol 2012;16(1):10-5.
[37] Verschuur HP, Rijksen G, van Oirschot BA, et al. Protein tyrosine (de-) phosphorylation in head and neck squamous cell carcinoma. Eur Arch Otorhinolaryngol 1994;255(1):12-6.

[38] Tabatabaeifar S, Larsen MJ, Larsen SR, et al. Investigating a case of possible field cancerization in oral squamous cell carcinoma by the use of nextgeneration sequencing. Oral Oncol 2017;68:74-80.

[39] Califano J, Van der Riet P, Westra W, et al. Genetic progression model for head and neck cancer: Implications for field cancerization. Cancer Res 1996;56(11):2488-92.

[40] Partridge M, Emilion G, Pateromichelakis S, et al. Field cancerisation of the oral cavity: comparison of the spectrum of molecular alterations in cases presenting with both dysplastic and malignant lesions. Oral Oncol 1997;33(5):332-7.

[41] Bremmer JF, Braakhuis BJ, Brink A, et al. Comparative evaluation of genetic assays to identify oral precancerous fields. J Oral Pathol Med 2008;37(10):599606.

[42] Califano J, Westra WH, Meininger G, et al. Genetic progression and clonal relationship of recurrent premalignant head and neck lesions. Clin Cancer Res 2000;6(2):347-52. 